\title{
NARRACIONES Y EMOCIONES EN TIEMPOS DE CAMBIO E INCERTIDUMBRE
}

\section{Narrations and Emotios in Times of Change and Uncertainty}

Fecha recepción: 17 de marzo de 2021 / fecha aceptación: 15 de mayo de 2021

Anna M. Fernández Poncela ${ }^{1}$

Cómo citar este artículo:

Fernández Poncela, A. (2021). Narraciones y emociones en tiempos de cambio e incertidumbre. Revista Pensamiento y Acción Interdisciplinaria, 7(1), 56-75. http://doi.org/10.29035/pai.7.1.56

\section{Resumen}

El objetivo de este texto es un recorrido emocional en tiempos de pandemia a través de la narración de un grupo de estudiantes universitarios. Se parte, en primer lugar, de la importancia de la narrativa como expresión social y práctica terapéutica. Así como, en segundo lugar, de la importancia de las emociones en momentos de amenazas, cambios e incertidumbres, y de su expresión que alivia. Con estas dos premisas se solicitaron relatos sobre los sentimientos vividos en el contexto de la pandemia en la primavera del año 2020. Se conjuga investigación con práctica social, se salva el distanciamiento físico y se propicia la introspección, reflexión y expresión emocional. Los resultados de este ejercicio escritural emocional, remarcan los beneficios de la narración, y se comprueba el clima emocional en tiempos de cambio, dominado por el miedo, el enojo y la tristeza, además del estrés, la ansiedad y la tensión, vividos por la situación de la alerta sanitaria y las medidas de confinamiento.

Palabras clave: emociones, investigación, narraciones, pandemia, terapia.

1 Doctora en Antropología Cultural, Investigadora y docente del Departamento de Política y Cultura, División de Ciencias Sociales y Humanidades, Universidad Autónoma Metropolitana/Unidad Xochimilco (UAM-X). Correo electrónico: fpam1721@correo.xoc.uam.mx 


\begin{abstract}
The objective of this text is an emotional journey in times of pandemic through the narration of a group of university students. It starts, first of all, from the importance of the narrative as a social expression and therapeutic practice. As well as, secondly, the importance of emotions in times of threats, changes and uncertainties, and their expression that relieves. With these two premises, stories were requested about the feelings experienced in the context of the pandemic in the spring of 2020. Research is combined with social practice, physical distancing is saved and introspection, reflection and emotional expression are encouraged. The results of this emotional writing exercise highlight the benefits of storytelling, and the emotional climate in times of change is verified, dominated by fear, anger and sadness, in addition to stress, anxiety and tension, experienced by the status of the health alert and containment measures.
\end{abstract}

Keywords: emotions, research, narratives, therapy, pandemic.

\title{
Introducción
}

Aquí tiene lugar un acercamiento a las emociones y sentimientos a través de su descripción y narración en época de la pandemia del 2020. En particular indagar los afectos más sentidos en los momentos álgidos de la alerta sanitaria. Ello se hace mediante un redactado de universitarios. En concreto narraciones a modo de testimonios emocionales sobre el coronavirus y el quedarse en casa. Se trata de indagar el mundo emocional de un grupo de jóvenes estudiantes en los momentos álgidos de la alerta sanitaria por la COVID-19 en la ciudad de México. Esto a su vez sirvió para ejercitar la escritura narrativa con intención académica, y también, especialmente, a modo de cierto ejercicio de carácter terapéutico, con objeto de aliviar al estudiantado tan presionado en aquellos días. La investigación social y la práctica reflexiva y terapéutica se conjugaron a través de un medio posible en el confinamiento: la narración escrita. Y eficaz en dos sentidos, en primer lugar, proporcionar información acerca del tema a estudiar, toda vez que esto se combina con la capacidad del instrumento para la exposición y autorreflexión, así como, cierto alivio de la tensión vivida de quien participa. Una doble adaptación a las herramientas de investigación, y a las necesidades de las y los jóvenes estudiantes universitarios en momentos de estrés y temor.

La escritura es una excelente compañera de la introspección personal y el alivio emocional. La narración es una forma de estructurar, organizar y expresar vivencias (Bruner, 2001), que al hacerlo se convierten en experiencias (Rogers, 2007), y se las puede iluminar con la introspección y la conciencia, entre otras cosas, como obtener cierto alivio en épocas inciertas y estresantes. Las emociones en momentos convulsos no solo se desequilibran muchas veces, sino que llegan a intensidades dolorosas y devienen sentimientos que conducen al sufrimiento, de ahí su necesidad de sentir y transitar, de poner consciencia y transmutar, en la medida de lo posible. 
Con objeto de contextualizar un poco el caso de México, decir que la Secretaría de Educación suspendió clases el 20 de marzo del 2020 siguiendo las indicaciones de la Secretaría de Salud. En particular, en el estudio de caso aquí presentado que corresponde al espacio universitario, el 19 de marzo se decidió continuar trabajado, pero en modo no presencial. De hecho, a mediados de abril, se aprobó regresar a clases a distancia a partir de mayo, en principio provisionalmente. Añadir que, pese a la polémica política sobre las medidas y acciones del gobierno en torno a la pandemia, se siguieron las indicaciones oficiales, y las instituciones y los medios reiteraron los discursos y protocolos internacionales. Por supuesto, como en todo el mundo, circularon rumores o noticias falsas. Todo lo cual contribuye al desequilibrio mental y emocional, sobre todo tras el shock inicial cuando en el discurso del 11 de febrero, la OMS (2020) afirma que "nunca antes habíamos visto una pandemia generada por un coronavirus...Al mismo tiempo, nunca antes habíamos visto una pandemia que pudiera ser controlada... Hemos hecho sonar la alarma de forma alta y clara".

\section{Marco referencial}

\section{La escritura como terapia}

Brevemente una exposición sobre la importancia de la escritura y en especial la narrativa con objeto de sino liberar totalmente, sí aliviar parcialmente, las tensiones emocionales de las personas.

Para iniciar, decir que la escritura es un recurso personal que ayuda a sacar fuerzas del interior e incluso en ocasiones resolver conflictos al conectar con uno mismo, interpretar hechos, dar sentido a ideas, relatar experiencias. En particular el escribir sobre emociones fuertes relacionadas con eventos desestabilizadores y que provocan mucho sufrimiento, se considera algo más, cuando no satisfactorio, ya que de alguna manera dicha expresión de emoción ordena mentalmente los problemas, propicia la reflexión y transforma significados, incluso fomenta la estabilidad emocional necesaria para transformar pensamientos y conductas (Reyes-Iraola, 2014). Y es que la escritura sobre circunstancias emocionales conduce a escudriñar sobre el mundo interno (Kohan, 2013). Una forma de explicarse, ordenar, reconocerse (Adorna, 2014), e incluso entenderse y reconciliarse con uno mismo.

Se aconseja incluso escribir para vivir mejor y ser feliz, ya que se conecta emoción y pensamiento, se plantean problema y a veces su solución, en todo caso, es una suerte de resignificación de la historia personal, que posee poder analgésico, liberador, energetizante, en una palabra, sanador (Kohan, 2013). 


\section{La terapia de la escritura}

En concreto se emplea como forma terapéutica por varias corrientes psicológicas e incluso médicas (Rodríguez, 2011). Como técnica de trabajo emocional, que produce autoconciencia y conexión con sentimientos conscientes, y también, emociones bloqueadas o reprimidas, lo cual conlleva recuperar la propia voz, la autoestima, y en general, el bienestar psicológico (Redvisible, 2014). Porque los pensamientos van y vienen y la escritura provoca cierta distancia espaciotemporal, reorganización, autoobservación (Adorna, 2014). Y es que la escritura, se reitera, ordena el caos de un suceso traumático, para entenderlo y quién sabe si sobreponerse al mismo. En todo caso, sí colabora con el alejamiento del estrés y acercamiento al equilibrio emocional, esto es, la mejora de la salud y la vida (Rodríguez, 2011).

Particularmente, los estudios sobre el ejercicio de la escritura terapéutica propiamente dicha (Pennabaker, 1997), demuestran un beneficio emocional y corporal; ayuda a darse cuenta, entender y entenderse, reelaborar cuestiones y solucionar conflictos, incluidos los aspectos traumáticos personales, ya que se piensan y resignifican, en cuyo proceso se realiza un acercamiento a su resolución. Se provocan cambios emocionales, cognitivos y comportamentales, además de físicos, transformaciones en el procesamiento mental y afectivo de experiencias dolorosas, conflictivas y traumáticas (Pennabaker \& Beall, 1986). Se trata de vencer la inhibición, expresar y liberar la emoción de forma terapéutica (Pennebaker \& Seagal, 1999).

Entre varias de las técnicas, sobresale y seleccionamos aquí, la Terapia narrativa, misma que facilita observar diversos puntos de vista en torno a un conflicto, ya que al relatar experiencias se adquiere coherencia y sentido, es posible deconstruir el discurso dominante, reelaborar diferentes propuestas para ordenar la vida y adquirir significado (White \& Epston, 1993). Se adquiere conocimiento y nuevas perspectivas que colaboran con la transformación, al hacer más comprensible la vivencia y poder externar lo que causa sufrimiento (Payne, 2002). En este mismo sentido, es que se generan ideas diferentes y se perciben emociones hondas, escuchar varias voces y observar nuevas posibilidades (Penn \& Frankfurt, 2005). En fin, un camino de comprensión y liberación, hacia una vida más serena, presente y equilibrada.

\section{Emociones y sentimientos}

A continuación, se expone brevemente las definiciones de emociones y sentimientos, básicamente desde la perspectiva Gestalt, seleccionada por su claridad y practicidad para aplicarla y guiar la presente práctica y estudio.

Las emociones son programas y procesos mentales y físicos, que implican al cuerpo y al cerebro, y que reaccionan o surgen ante algo interno o externo, 
en general presentando manifestaciones observables, de forma intensa, rápida y espontánea, y generalmente breve, que tiene que ver con la consciencia inmediata. Los sentimientos son considerados como una suerte de emociones, pero se ubican más en la mente, se relacionan más con la cultura, duran más en el tiempo y son parte de la consciencia reflexiva (Damasio, 2006, Fernández, 2011, Filliozat, 2007; Marina, 2006). Tanto unas como otros provienen de la percepción y la sensación e informan de una necesidad (Muñoz, 2006) que en su camino a la satisfacción guía hacia la acción (Muñoz, 2009).

Las emociones no son positivas o negativas, aunque así las nombramos cuando unas animan y otras duelen. Las emociones son funcionales y satisfactorias o disfuncionales e insatisfactorias. Lo primero es cuando cumplen su función, por ejemplo, el miedo protege y el enojo defiende, así como, la tristeza sirve para introspectar, o la alegría vivifica. Si esto se realiza en la medida correcta todo transcurre con sentido y cumplen su función a cabalidad. Eso sí, pueden estar disminuidas o exageradas, surgir en un momento en que no parecen relacionadas directamente con lo que acontece en el entorno, sino que pudieran ser asuntos inconclusos, experiencias obsoletas o pensamientos catastróficos (Muñoz, 2009), y es ahí donde pierden su sentido funcional, y pueden ocasionar problemas físicos y mentales, personales y sociales, es ahí donde duelen mucho y son disfuncionales.

Sobre el tema hay enfoques más biológicos (Damasio, 2006; Casafont, 2014) y otros más culturales (Ahmed, 2015; Felmand, 2019); no obstante y obviamente, en ellas confluyen neurología, fisiología, cognición y sociedad (André \& Lelord, 2012; Fernández, 2011). Además, tras cierto tiempo del culto en las últimas décadas a las pasiones se está pasando a una época que intenta complementar y moderar emociones y racionalidad (Camps, 2012). Eso sí, lo anterior es algo difícil en una coyuntura de trauma (Levine, 2013) y catástrofe (OPS, 2006), de incertidumbre y miedo (Bauman, 2007), como la que protagoniza este estudio. Reiterar el enfoque humanista de la terapia Gestalt como base que inspira la revisión emocional de los redactados estudiantiles.

\section{Metodología}

El método es cualitativo, la técnica es la narración (Bruner, 2001; Smorti, 2001). En cuanto al instrumento concreto, se trató de la solicitud de narraciones emocionales escritas, de cómo se sentían, en una ocasión con relación "al anuncio de la pandemia y la existencia del coronavirus" a nivel internacional según la OMS, y en otro, en cuanto al "confinamiento en casa" la campaña en México de "Sana distancia" y "Quédate en casa". La instrucción fue primero nombrar las emociones y con posterioridad escribir sobre ellas, describirlas y explicarlas, y narrar todo aquello que consideraran oportuno en torno a las mismas. Por supuesto, se siguieron nombrando a lo largo de toda la experiencia emocional 
testimonial relatada, no obstante, la primera referencia o enunciado de emoción es considerada la que más se sentía y por lo tanto importaba, o viceversa.

Así que se trató de dos narraciones diferentes, ambas a un mismo grupo de estudiantes conformado por veintidós mujeres y once hombres, 33 en total, de entre 18 y 20 años, de carreras de sociales de la Universidad Autónoma Metropolitana, plantel Xochimilco en la Ciudad de México, en el mes de mayo y vía on line, por las circunstancias. En mayo se estaba en pleno auge de lo que se nombró como primera ola en México, tras el anuncio a finales de marzo y la cuarentena establecida en abril con su pico en mayo. Aclarar y reiterar, que este estudio se basa en los dos redactados, 66 en total, uno por la pandemia y otro para la permanencia en casa. Tener presente que se trata de jóvenes, universitarios, residentes en la ciudad de México, con objeto de conocer el sujeto de estudio que participa en este ejercicio. A la hora del análisis de la información, se parte de la narración y se hizo básicamente guiado por las emociones, como indicador semántico, protagonistas de la redacción solicitada, en parte como análisis de contenido cualitativo con énfasis en el análisis temático del discurso (Verd \& Lozares, 2016).

Remarcar que los redactados tenían un triple propósito, por un lado, se trataba de una solicitud como parte de un ejercicio de expresión escrita para una materia de redacción, que se conjugó con la necesidad de expresión en esos momentos del estudiantado de lo que estaba pasado, y sobre todo, de lo que estaba sintiendo, y con el interés de quien investiga sobre el tema de los afectos, toda vez que la consciencia de su necesidad de expresión. Esto es, se trató de una práctica académica dentro de una materia, una suerte de terapia escritural, y una fuente informativa de investigación. Estas dos últimas cuestiones en el marco de las novedosas o diferentes formas que investigar que impuso la distancia social y el confinamiento; toda vez que las renovadas maneras de intervención, o mejor dicho acercamiento y acompañamiento, sino terapéutico propiamente dicho, sí amistoso, empático y solidario, en la medida de los posible, por supuesto.

La narrativa entreteje la experiencia personal y la realidad social (Bertaux, 2011), potencia la capacidad reflexiva (Giddens, 1994); y auto reflexiva (Nussbaum, en Modzelewski, 2014). 


\section{Resultados y discusiones:}

\section{Emociones y narraciones: un ejercicio académico, terapéutico, investigativo}

A continuación, se presenta la revisión y reflexión sobre la pandemia y el confinamiento, según las narraciones elaboradas por las y los estudiantes, centrando el análisis en las emociones expuestas y su expresión descriptiva y explicativa de las mismas. Si bien se trata de un grupo de jóvenes estudiantes universitarios, quizás sujetos similares, incluso actores sociales diversos pueden identificarse y sentir y expresar experiencias emocionales semejantes, en el marco social y coyuntura histórica concreta.

\section{El miedo imperante frente a la pandemia y al coronavirus}

Sin lugar a dudas, la emoción que reina ante la pandemia y el coronavirus es el miedo, a mucha distancia de cualquier otra de las nombradas y redactadas, tales como, el enojo y frustración, o la tristeza y depresión, incluso el estrés.

Brevemente definir el miedo como la reacción de alguien que percibe una amenaza que conduce a la protección, a veces con huida, otras con parálisis, incluso con enfrentamiento. Si bien la sensación es desagradable, facilita si es funcional, la mencionada protección (Muñoz, 2009). El miedo es la emoción más sentida en la historia y en la actualidad (Delumeau, 2009, Robin, 2009), y el miedo último y primigenio, consciente o inconscientemente, es a la muerte (Bauman, 2007).

62

El miedo, a veces nombrado con la levedad de la preocupación que puede llegar a ser prudencia y prevención, y otras con la fuerza del pánico que puede desencadenar patologías personales y terrores sociales.

Para empezar, se contabilizaron las emociones enunciadas en los 33 redactados, solo con objeto de mostrar su existencia y expresión numérica que corresponde con la inquietud vivida, y únicamente se presentan las que aparecen de forma reiterada no las lo que lo hacen de forma única. Como se observa en el cuadro 1, el miedo seguido de la incertidumbre, ambos relacionados, son las mayoritariamente nombradas. Luego hay otra serie de emociones desde el enojo al desánimo que tienen que ver con lo que se denominan emociones negativas en el sentido que suelen producir sufrimiento sobre todo si se convierten en sentimientos y no son funcionales, según lo ya dicho con anterioridad. También se observa en el cuadro, solidaridad, empatía y amor, emociones y sentimientos que producen sensaciones agradables y que también son nombradas en diversas ocasiones. Señalar que el estrés o la preocupación como tales no son emociones, se trata más bien de estados mentales-emocionales, no obstante, se han incluido por su carácter eminente y evidentemente emocional y su reiterada mención. 
Otras veces se observa parte de una familia emocional, como el miedo y la incertidumbre o el pánico; o el caso de la tristeza, la depresión y el desánimo; pero se decidió presentarlas por separado dado su importante número de exposición en sus diferentes versiones e intensidades. En todo caso y si bien se muestran con más detalle a continuación con fragmentos narrativos de experiencias relatadas, hay que señalar desde un inicio que el miedo-y sus conceptos afines-, el enojo y la tristeza, sobre todo el primero, como emociones básicas y primarias son las que destacan aquí.

\section{Cuadro 1.}

Emociones ante la pandemia y el coronavirus

\begin{tabular}{lr}
\hline Miedo & 27 \\
Incertidumbre & 12 \\
Estrés, ansiedad & 11 \\
Enojo (frustración) & 10 \\
Tristeza & 7 \\
Depresión & 6 \\
Apatía & 5 \\
Preocupación & 3 \\
Pánico & 3 \\
Desánimo & 2 \\
\hline Solidaridad & 9 \\
Empatía & 8 \\
Amor & 3 \\
\hline
\end{tabular}

Fuente: Elaboración propia

El miedo sobre todo al contagio y a la enfermedad-y en su caso a la muerte-, la propia y la de un familiar, y "miedo al virus", como se dijo en más de una ocasión. Lo cual provoca la decisión de "no querer salir" o la preocupación "por un deceso familiar". Un miedo que en algunos casos se intensificó porque "tuve gripa" o porque "estuve histérica de la enfermedad llegué a pensar que la tenía", esto es, por algo real o incluso por algo imaginario. El miedo focalizado en la pandemia, el virus, la enfermedad y la muerte. Esta última el miedo primigenio y básico (Bauman, 2007), como se dijo.

Todo lo cual provoca estrés y ansiedad que son descritos como "opresión en el pecho" y "un nudo en la garganta". Estrés por "el cambio de vida", "la situación de salud fuera de control", todo un reto cuando el mundo y los hábitos se trastocan, y la incertidumbre se presenta de golpe y sin avisar. Estrés que es 
reacción fisiológico, respuesta del organismo, ante estresores externos o internos (Seyle, 1956).

Y la incertidumbre por "no saber qué ocurre", "qué pasará", "pensar en el futuro", "la economía del país", "los contagios y los muertos", incluso la "mala información y los chismes". "Las noticias van de un lado a otro y ya no se sabe con qué información quedarse". Esta emoción se reitera en el sentido de "cuándo terminará", “¿terminará?", "¿regresaremos?", "se volverá a las actividades", en fin varias oraciones en el tono de "no saber sobre la nueva realidad...pensar que tarde o temprano las cosas terminarán y cómo tomará su curso...cómo afrontar la nueva realidad". Incertidumbre de no saber y carecer de seguridades.

También hay tristeza declarada "cuando me quedo viendo noticias", "cómo las familias sufren por las pérdidas de familiares", "no tienen dinero para medicamentos". Lo cual provoca "fatiga física y emocional", "pesadez mental y física", una sensación de "no poder más". "A veces personas de la familia comienzan a caerme mal por no respetar las reglas para evitar la propagación del virus...tristemente el trato con el otro suele ser conflictivo". La tristeza por diversas circunstancias según se observa.

A veces depresión porque "todo está muy mal", "diariamente se muestra en la televisión y en las redes", "Siento depresión, solo puedo esperar que esto se disipe y volvamos a nuestra normalidad".

Y también desánimo, "no tengo ganas de hacer nada", "los proyectos postergados", "no puedo trabajar". La apatía aparece ligada a la tristeza y la depresión, y se es consciente que hay que salir de ahí, "estoy en el esfuerzo por disminuir la apatía y la tensión en mí". Preocupación porque "la gente se informa en cualquier lugar y en fuentes de mala información" y "los rumores llegan a confundir y eso preocupa".

En ocasiones hay enojo y frustración, y "hasta me provoca pesadillas", pero sobre todo "el no saber". Frustración y consternación por "no poder trabajar", "solventar los gastos", "hacer planes", "seguir con mi vida".

Enojo en particular con "la gente que no tiene conciencia", el coraje con quienes "dicen que no existe", a "los que no le dan importancia", "por su culpa hacen que el confinamiento se alargue", y molestia porque "las personas no toman las medidas", "ellos tienen la oportunidad de cuidarse y no". En alguna ocasión aparece la palabra molestia o preocupación, no obstante, en el relato se observa el enojo: "personas pueden evitar salir, no lo hacen, no piensan en las consecuencias, eso me molesta". Tal vez aparece la figura del "chivo expiatorio" (Girard, 1983), cuando la responsabilidad de una forma de vida, organización social, enfermedad y sistema político y sanitario se traspasan a la población. 
En otro orden emocional se expresa la empatía, la solidaridad y el amor. El amor "con los seres queridos" y la solidaridad con todos los "que la necesitan", "me alegra participar en los grupos de apoyo a los necesitados". Parte del deseo expresado de que "todos estemos lo mejor posible y sanos". La empatía con la "red de apoyo" a "familiares y amigos". "He donado a una organización para apoyar a personas que perdieron el empleo", "ayudar a las personas en riesgo en sus compras, hay que cuidarnos con amor".

El amor junto al autoconocimiento o la autoconsciencia, quizás provocado por la introspección de la tristeza y la consciencia aparece en alguna ocasión, reflexión que se expande a lo social: "me hizo ser una persona más consciente de lo afortunada que soy...tengo techo, comida, salud" o "es el momento de trabajar en la persona que siempre he querido ser...y también ver por los demás". Aunando reflexión y auto reflexión (Giddens, 1994; Nussbaum en Modzelewski, 2014).

También dijeron sentir motivación por "ocuparse de cosas nuevas", incluso nombraron la resiliencia tan importante ante la amenaza y la vulnerabilidad (Cyrulnik, 2007). Finalmente, hay quien expresa "hay que luchar y no rendirse" como si de una lucha, batalla o guerra se tratara. Y hubo expresiones como orgullo y entusiasmo para "combatir" lo que pasa y esfuerzo para "sentirse mejor". "Siente que lo puedes todo y una situación diferente o un obstáculo es para el bienestar que anhelamos". En fin, expresiones muy diversas.

En varias ocasiones y en las narraciones sobre las emociones con relación al coronavirus y la pandemia se observa claramente una ambivalencia con el otro o los otros. Entre el amor y la solidaridad versus el enojo. Lo primero, porque varios relatos hablan de "apoyar" y "ayudar", de desarrollar la empatía hacia "los otros", "los enfermos", "los pobres". Y también otros testimonios, o incluso en los mismos relatos, aparece el discurso que responsabiliza "al otro" y lo condena porque "no creen", "no cumplen" y "por su culpa hay enfermos", incluso afirman que "los castigaría si pudiera".

A continuación, los relatos sobre el confinamiento, desbordados en un sinnúmero de expresiones emocionales, diversas, duras, claras, sentidas y en general padecidas y sufridas. 


\section{Ansiedad, estrés, frustración, tristeza y fatiga, ante el confinamiento en casa}

Una miríada emocional fue descrita en el caso del confinamiento, esto es, varias son las emociones señaladas como importantes, y no solo eso, cada una de ellas nombrada con su familia de conceptos afines (Cuadro 2).

Es posible observar que aparecen todas las emociones básicas: miedo, amor/ afecto, tristeza, enojo, alegría. La definición de afecto o amor, significa vinculación, abre al ambiente y se siente de manera agradable. En cuanto a la tristeza se relaciona ante la pérdida o desilusión, si bien se siente de forma desagradable conlleva parar, introspectar, reflexionar. El enojo convoca a poner límites a una invasión, se percibe como desagradable, no obstante, alerta sobre la necesidad de defensa. La alegría tiene que ver con la satisfacción sobre algo, vivifica y da energía (Filliozat, 2007, Greenberg \& Paivio, 2007, Muñoz, 2009).

Por supuesto, domina el estrés, que no es emoción en sí como ya se dijo, y su campo semántico: nerviosismo, tensión, preocupación, desesperación con muchas menciones. Luego está la tristeza con su campo respectivo, la depresión y el desánimo nombrada en varias ocasiones. A la cual es posible añadir la fatiga y el agotamiento que tienen que ver con esta y también con el cansancio imperante en sectores de la sociedad actual (Han, 2014) al parecer agudizado con el encierro. No podría faltar el enojo y la frustración con sus señalamientos ante la situación de alarma social, las medidas y sus consecuencias. Y el miedo que prosigue, ya que gobierna en el anuncio de pandemia y se extiende al confinamiento, o sea, nunca se va, de hecho, lo mencionan junto a los conceptos afines en diferentes ocasiones, si bien en las circunstancias del quedarse en casa se ve superado por el sentir de otras emociones u opera junto a estas. No nos hemos olvidado de la ansiedad, que aquí se ha puesto cerca del estrés y nerviosismo, ya que se trata más que nada de sensaciones y síntomas, y que, si bien acompaña al estrés, por supuesto, también es compañera del miedo. En todo caso, en las transcripciones se va desenvolviendo el significado de la elección de la emoción en concreto por parte de cada quien. Añadir que en numerosas ocasiones se describió el "estar todo el día en casa", sin embargo, en concreto la palabra "encierro" literal apareció en muchas veces de forma directa. Un estar en casa, pero desde la perspectiva de obligación, resignación, a modo de cárcel o prisión, más que precaución o protección, que supuestamente salva la vida, pero que rompe la libertad y la alegría. 


\section{Cuadro 2.}

Emociones ante el confinamiento y el quedarse en casa

\begin{tabular}{lr}
\hline Ansiedad & 16 \\
Estrés & 10 \\
Nerviosismo, tensión, preocupación, desesperada & 12 \\
Tristeza, depresión, desánimo & 14 \\
Fatiga, agotada & 10 \\
& 15 \\
Frustración, enojo & 11 \\
\hline Miedo, incertidumbre, pánico, angustia & 3 \\
\hline Solidaridad & 3 \\
Empatía & \\
Amoliz, alegría & \\
\hline Reflexión & \\
\hline
\end{tabular}

Fuente: Elaboración propia

Como se mencionó ansiedad puede ser de la familia del miedo como del estrés, y por supuesto, estrés y miedo van de la mano, como se sabe en el estrés postraumático (Levine, 2013). Sin embargo, por razones de clasificación se separaron, y a través de los significados expuestos y las interpretaciones realizadas, se considera que la ansiedad en este caso está más próxima al estrés del encierro que al miedo al virus, por decirlo de manera directa. De hecho, como una forma de expresar su ansiedad o estrés, en su caso cuando se juntas ambas expresiones, se aludió al "encierro" o "encerrados", de forma reiterada e intensa: "encerrada todo el día en casa" o "encerrado y viendo noticias a toda hora", "el encierro y la inactividad física es lo que más pesa". Ya en concreto, al nombrar la ansiedad sola, aparece "el distanciamiento de las personas", "el no acudir a sitios", "modificar hábitos", hasta "el perder el control de tu vida", o sea, cambio de costumbres y desorientación total. Por su parte, el estrés obedece al "estar en casa sin salir", "no ver ni conversar con amigos", "la rutina" o "el desorden de los horarios", todo un cúmulo de abruptas y obligadas transformaciones en la vida personal y social, y en todos los ámbitos, pareja, familiar, amistades, de ocio, laboral y escolar.

También el nerviosismo-producto del estrés- es resultado de "no poder, no tener dónde descargar tu energía". La tensión "todo en casa, un lugar incómodo, el convivir todo el día con la familia, trabajo y escuela", sobre todo "no poder salir" y el "constante encierro", "ya no puedo más". "Desesperada ya estoy por la falta de ejercicio, no realizar actividades, por el constante de todo, la flojera". 
Además del añadido de la queja, bien concreta por el sector que narra, de las clases a distancia, que producen estrés, ansiedad, nerviosismo: "no me concentro en clases", "no puedo trabajar bien lo de la escuela", "me distraigo con las clases en línea", "no me gusta las clases on line", "muchas tareas" y "ya quiero regresar a la escuela", "quiero ver a mis amigos". En alguna ocasión sí apareció una valoración diferente en el sentido que "incluso la tarea a veces le encuentro gusto" porque "me distrae de lo que pasa", no porque agrade, sino porque evade de algo peor, hay que aclarar.

La tristeza "por mi pasado" o "rodeada todo el día de lo mismo, sin poder despejarme", "todos los días son iguales". La fatiga por "estar acostado, dormir todo el día". "Agotada porque no me organizo bien", "me duermo tarde", "tengo insomnio". Y la apatía "no tengo ganas absolutamente de nada".

El enojo, sobre todo, "por la gente sin empleo" y también "por no poder hacer lo que me gusta", "no hacer ejercicio y deporte me frustra", "enojo por el encierro", "no tener privacidad", hasta "las discusiones familiares" y la queja de "tanta convivencia". A veces sí se alude al "estrés, enojo, frustración por la convivencia con la familia". Aunque en ocasiones se toma como un reto, pues es una "oportunidad de conocernos mejor, convivir más y limar asperezas". Y es que enoja "no poder salir", "querer que acabe", y además "lloro y no me gusta y estoy enojado". O sea, enojo por los problemas de la gente para su sobrevivencia, y por la imposibilidad de salir, ejercitarse o realizar actividades que gusta fuera del hogar, o por la forzada convivencia familiar, no siempre en las mejores condiciones, si bien esto también conlleva el apoyo y solidaridad parental. Enojo porque "quiero regresar a mi vida, salir de mi casa...aprendí que mi paciencia es poca". Autoconocimiento incluido, como ya se mencionó con anterioridad.

A este enojo se suma de forma más o menos ligera el que "mi tío y mi abuela no se cuidan como deberían y siguen saliendo a la calle sin necesidad". Aunque en general es de manera más contundente, "mis vecinos que dicen que no existe el virus y no respeten las medidas sanitarias y el confinamiento", y es que "las personas no se informan bien y se toman a la ligera esto, y suponen que es un invento mundial", "son unos irresponsables", "los individuos ignoran, salen a las actividades cotidianas, caminan por las calles, hacen caso omiso a las normativas, si siguieran las normas todos saldríamos más pronto", "por ese tipo de gente no va a parar el problema, la culpa es de ellos, no va a parar el problema". Solo como curiosidad señalar que aparece la figura del "chivo expiatorio" (Girard, 1983) en el otro, el que incumple las medidas y es culpable del contagio y que la enfermedad se prolongue, entre otras cosas; ninguna mención de las implicaciones de origen y causas internacionales, ni de las problemáticas o limitaciones de las políticas estatales, ni de la sanidad pública y su precariedad; concentración en los infractores que al parecer reproducen y subliman el enojo. 
La incertidumbre especialmente por "la economía, el trabajo y el país", "no saber cuánto tiempo más", "no saber qué va a pasar", "cuánto tiempo dure el estado de crisis", además de cuándo poder volver a "las actividades recreativas". El no saber es principalmente lo que corroe y provoca incertidumbre, que como se vio, es también parte del temor.

$Y$ de nuevo el miedo, un miedo que a veces confiesan es "muy fuerte", porque "las personas cercanas ya se contagiaron y fallecen", "las personas nos seguimos informando, no disminuyen los enfermos...nos preocupamos...la situación está mal y quisiéramos salir lo antes posible", "la angustia por salir de este encierro", y es que parecen "bombas las malas noticias, llegan a diario de muertes", "cada cinco minutos bombardean con estadísticas, contagios y mortalidad", "todo el día en casa con noticias 24 horas, en la TV y en las redes y la familia, los casos de contagios que crecen y las muertes en aumento", "cada que suena el teléfono pienso que es para decirnos que alguien se contagió, o pero aún que se murió", incluso el pánico "en todas partes, en la TV...hablan del tema, lo único que provocan es más sentimientos negativos y que si incumplo algo mi conflicto emocional". Como se observa y aparece en varias narraciones, las noticias, sobreinformación, desinformación, causan malestar y zozobra.

En medio de las emociones desagradables y que duelen, aparecen algunas que no, como la empatía pues "para superar episodios de ansiedad intento ayudar a las personas que amo, escucharlas, leerlas, procurar más a mis allegados", "Empatía con mi familia, mi papá, mi mamá, mi hermano y mi hermana", "Solidaridad con la familia amorosa que tengo". En fin, emociones y sentimientos satisfactorios que acompañan y contienen. Algo a señalar es que a pesar de problemas de convivencia intensa y forzado, también se apunta el acompañamiento y color emocional que la familia aporta, siendo en general, revalorizado.

En alguna ocasión apareció la palabra reflexión como respuesta a la solicitud de emoción, sin embargo, y sí el relato giraba en torno a los sentimientos en tono existencial. "Reflexiono que muchas veces hemos perdido el tiempo con la tecnología", "no se dio importancia a lo importante", "un momento para reflexionar y cambiar el curso de nuestras vidas", "pienso que aprendí de mi paciencia". En fin, hay quien afirma que todo esto es una excusa "para reflexionar sobre el mundo, sobre cada quien", que podría ser un resumen de lo dicho con anterioridad, en el sentido de provocar y fomentar el autoconocimiento y la reflexión social, la pandemia, las medidas, e incluso la narración solicitada.

Además del ir y venir entre el abrazo a la emoción y al esfuerzo del evitamiento sobresale, "la importancia de dedicar un espacio de tiempo a permitirnos sentir miedo, ansiedad o frustración, o lo que nos pueda estar produciendo el confinamiento", y no faltan los testimonios contrarios, "los pensamientos negativos, trato de no darles vida", "evito entrar en contacto con emociones negativas y perturbadoras", "huir del encierro con la mente y evitar que duelan las emociones". 
O aquellos que manifiestan tranquilidad pues la familia está bien en casa, hay comunicación virtual con amistades, se trabaja y estudia en el hogar, y el entorno cercano parece estar bien y ser benéfico, "pues tengo una feliz convivencia familiar" o "estoy feliz porque tengo una familia muy buena, tenemos más tiempo para platicar y jugar", "teníamos mucho tiempo que no convivíamos y nos dábamos amor fraternal y ahora lo puedo hacer". Y hay quien siente alegría "por la naturaleza y el medio ambiente...menos contaminación...respiro naturaleza". En fin, como se dijo al inicio de este apartado el confinamiento exhibió una paleta emocional de colores variopintos, producto seguramente de lo que cada quien lleva en su interior, el contexto social y familiar, las creencias y los valores, las fortalezas mentales y equilibrios emocionales.

\section{Los beneficios de la escritura en la expresión emocional}

Aquí se subraya la caricia de alivio que significó expresar lo que sentían, pensarse, sentirse, soltarse, desahogarse, todo lo que implica expresar ese nudo o peso emocional que ataba y pesaba en el cuerpo y en la mente; y que la escritura si bien no soluciona o sana del todo, sí permite una válvula de escape, de conocer y reconocerse, de auto observarse, acompañarse y valorar los sentimientos como compañeros de vida que van y vienen en etapas, y hay que abrazarlos para luego dejarlos ir. Por otra parte, están los testimonios presentados con anterioridad que tienen que ver con la reflexión (Giddens, 1994; Nussbaum en Modzelewski, 2014), esto es, el confinamiento en especial les dio tiempo, y quizás la pandemia premura, para ponerse a pensar sobre su vida, incluso en sentido existencial, además y por supuesto, emocional por la indicación del ejercicio, dada. Una suerte de escucha, de petición de opinión, acercamiento, reconocimiento, toda vez que la posibilidad de expresión, externar un dolor, observarlo y compartirlo, entre otras cosas (Rogers, 1993).

Algunas expresiones directas o indirectas en los redactados daban a entender que su escritura les había servido para una suerte de distensión y descanso, percatándose de la función terapéutica de la escritura de forma espontánea, y tal fue su nivel de conciencia que incluso lo agradecían en varios relatos, especialmente hacia el final de los mismos, a modo de reflexión y agradecimiento.

Explícitamente escribieron: "en realidad el reflexionar, he aprendido en lo que consiste el amor verdadero", "he pensado mucho sobre mis emociones, mi adicción a la tecnología, mi adicción a la noticias, mi vida pasada y lo que ya no quiero", y es que se puede cambiar porque "el amor somos todos, un sentir tan hermoso que nos glorifica el corazón", "el escribir ha sido un darme cuenta de muchas cosas que me están pasando, y un tanto liberador de poder decir lo que siento en este terrible encierro" . Finalmente: "Hasta cierto punto creo que escribir esto me ha librado del estrés del día". 


\section{Conclusiones}

Finalmente, y como se dijo en el apartado correspondiente, la escritura y en concreto la narración, poseen un carácter terapéutico, en el sentido de procesamiento cognitivo y afectivo de un trauma emocional, ya que facilita la expresión del dolor y sufrimiento, un ejercicio introspectivo de sacar, distanciar, organizar y reelaborar el proceso vivido (De Barbieri en González, et al, 2014). Aquí se reconoce tanto la importancia de la escritura como terapia (Kohan, 2013); así como, la terapia de la escritura (Adorna, 2014). Y si bien esto fue un ejercicio narrativo, aunó acercamiento terapéutico, investigación psicológico-social, práctica escritural y desarrollo de conciencia personal y social. Esto último, hay que remarcarlo por el proceso de darse cuenta (Stevens, 2006) que tuvo lugar, así como, la auto reflexión emocional que significó (Nussbaum en Modzelewski, 2014). Por lo que es posible afirmar que se cumplió el objetivo de recorrido emocional en tiempos de pandemia a través de narraciones, lo cual se comprueba con la información obtenida y presentada a lo largo de este artículo. También se comprueba no solo la importancia de la relación escritura y terapia, enunciada con anterioridad, sino su aplicabilidad en los ejercicios narrativos realizados, y con los ejemplos dados de agradecimiento por la práctica, y el alivio emocional y reflexión personal y social a la que este contribuyó. Todo ello explícitamente expuesto.

El miedo unió y conmovió ante la pandemia anunciada y un rosario de distintas emociones y sentimientos colorearon el quedarse en casa. En resumen, es posible afirmar que el miedo fue la emoción mayoritaria ante la declaración internacional de pandemia. En cuanto al confinamiento producto de la declaración anterior, se compuso de una melodía emocional variopinta, siempre con emociones desagradables, insatisfactorias y dolorosas, aunque con sus excepciones. Así, reiteramos según la información obtenida, miedo, incertidumbre, estrésansiedad, enojo-frustración, fue el resultado del anuncio de la declaración de pandemia. Miedo a descubrir y sentir la vulnerabilidad emocional individual y colectiva, quebrar seguridades mentales y comportamentales establecidas, interrupción de rutinas, enfrentarse a un discurso oficial de contagios, enfermos y muertes a través de noticias a su alrededor, según relatan. Miedo que conlleva incertidumbre, que provoca estrés y ansiedad. Miedo como amenaza anticipada a la posible finalización de la vida, el básico y principal y último de los miedos (Bauman, 2007).

Por otra parte, la ansiedad, el estrés, nerviosismo, tristeza y fatiga que aseguran comporta la cuarentena y el encierro, inquietud y zozobra, y también introspección, tiempo y espacio para la reflexión. Un detenerse a pensar sobre la existencia en general, su vida particular y la sociedad. Un recoveco, sino de calma, sí de oportunidad, para valorar lo que hoy se tiene, se es, para rectificar el camino caminado si es el caso, con valorización y agradecimiento explícitos hacia la amistad y en particular la familia. Un movimiento hacia el otro que lo 
reconoce y valora. Si bien con la excepción del enojo cuando este no se comporta como se espera o desea según la normativa oficial y según el discurso unificado de organismos internacionales, gobiernos y medios.

Tres cuestiones básicas e interesantes a destacar por su fuerza a través de la reiteración e intensidad en el presente estudio con base a la escritura, y que pudieran repercutir en el futuro próximo. Por un lado, el enojo y la solidaridad. El erigirse acusadores y jueces del prójimo como culpable, condenable y castigable al ser la causa de que sigua la enfermedad por no respetar las medidas de sanidad, cuestión esta que provoca desunión, enfrentamiento, intolerancia, y quién sabe en qué derive. Por otro lado, el apoyo mutuo y la solidaridad, la empatía con los otros, los que precisan ayuda y los que no se pueden cuidar por sus condiciones sociales, los que sufren las consecuencias de la pandemia.

Otro aspecto también importante para subrayar, el rol central de la familia como grupo central de pertenencia y sobrevivencia material y emocional en esos momentos, con relaciones íntimas ampliadas y profundizadas por las circunstancias, y sobre todo, ahora cultivadas y revalorizadas, el núcleo básico de acompañamiento y contención. Sin desconocer los problemas de convivencia y discusiones como se dijo en alusión al confinamiento.

Y un tercero, ya mencionado, pero oportuno reiterarlo: el parón y encierro que obliga a pensar y sentir, replantearse las formas de vida vividas y ofrece la elección de cómo se quiere en realidad vivir. A lo cual se suma el ejercicio de reflexión que la narración ofrece, ampliando y profundizando lo anterior, entre otras cosas ya dichas.

Como se suele decir, lo importante no es lo que pasa sino cómo se toma lo que pasa, en este sentido y más allá de la pandemia y el confinamiento, este trabajo se ha centrado en las emociones y sentimientos que aparecieron, y su explicación por parte de un grupo de jóvenes estudiantes, que en la narración elaborada pudieron darse cuenta de la vivencia y tuvieron la oportunidad de convertirla en experiencia (Rogers, 2007). Además, se considera que cada quien saca lo que lleva dentro, así las cosas, puede interpretarse que fue ocasión para ver y observar el miedo, enojo y tristeza, que llevamos en nuestro interior, para sacarlo y sentirlo y soltarlo, si es el caso. Así también, la empatía y el agradecimiento y la valoración por la vida. 


\section{Referencias bibliográficas}

Ahmed, S. (2015). La política cultural de las emociones. UNAM.

André, C. \& Lelord, F. (2012). La fuerza de las emociones. Kairós.

Adorna Castro, R. (2014). Practicando la escritura terapéutica: 79 ejercicios. Desclée De Brouwer.

Bauman, Z. (2007). Miedo líquido. La sociedad contemporánea y sus temores. Paidós.

Bertaux, D. (2011). El enfoque biográfico: su validez metodológica, sus potencialidades, Acta Sociológica, 56, 61-93. http://dx.doi.org/10.22201/fcpys.24484938e.2011.56.29458

Bruner, J. S. (2001). Actos de significado: más allá de la revolución cognitiva. Alianza.

Bruner, J. S. (2012). Realidad mental y mundos posibles. Gedisa

Camps, V. (2012). El gobierno de las pasiones. Herder.

Casafont, R. (2014). Viaje a tu cerebro emocional. Ediciones B.

Cyrulnik, B. (2007). La maravilla del dolor. El sentido de la resiliencia. Granica.

Damasio, A. (2006). El error de Descarte. La emoción, la razón y el cerebro humano. Crítica.

Delumeau, J. (2009). El miedo en occidente. Taurus.

Felmand, L. (2019). La vida secreta del cerebro: Cómo se construyen las emociones. Paidós.

Fernández Poncela, A. M. (2011). Antropología de las emociones y teoría de los sentimientos. Versión Media, 26, 1-26.

Filliozat, I. (2007). El corazón tiene sus razones. Conocer el lenguaje de las emociones. Urano.

Giddens, A. (1994). Consecuencias de la modernidad. Alianza.

Girard, R. (1983). El chivo expiatorio. Anagrama.

González-Rodríguez, S., Cantabrana, B. \& Hidalgo, A. (2016). El poder terapéutico de la narración. Revista de Medicina y Cine, 12(2), 110-121. https://revistas.usal.es/index.php/medicina_y_cine/article/view/15005 
Greenberg, L. S. \& Paivio, S.C. (2007). Trabajar con las emociones en psicoterapia. Paidós.

Han, B. C. (2014). La sociedad del cansancio. Herder.

Kohan, S. A. (2013). La escritura terapéutica. Alba.

Levine, P. (2013). Sanar el trauma: un programa pionero para restaurar la sabiduría de tu cuerpo. Neo Person.

Marina, J. A. (2006). El laberinto sentimental. Anagrama.

Modzelewski, H. (2014). Autorreflexión y educación de las emociones para la democracia. Entrevista a Martha Nussbaum. Areté. Revista de Filosofía, 26(2), 315-333. http://revistas.pucp.edu.pe/index.php/arete/article/view/11111

Muñoz Polit, M. (2006). Las necesidades desde el punto de vista de la psicología Gestalt. Psicología Humanista, 2, 15-25.

Muñoz Polit, M. (2009). Emociones, sentimientos y necesidades. Una aproximación humanista. IHPG.

Organización Panamericana de la Salud (OPS) (2006). Guía práctica de salud mental en desastres. OPS.

Payne M. (2002). Terapia narrativa: una introducción para profesionales. Paidós.

Penn, P. \& Frankfurt, M. (2005). La creación de un texto participante: la escritura, las voces múltiples y la multiplicación de narrativa. En G. Limón Arce, (Comp.), Terapias postmodernas: aportaciones construccionistas (pp. 25-37). Pax.

Pennebaker, H.W. (1997). Opening Up. The Healing Power of Expresing Emotions. The Guilford Press.

Pennebaker, H.W. \& Beall, S. (1986). Confronting a Traumatic Event: Toward and Understnading of Inhibition and Disease, Journal of Abnormal Psychology, 95(3), 274-281. http://doi.org/10.1037//0021-843x.95.3.274

Pennebaker, H.W. \& Seagal, J.D. (1999). Forming a Story: The Health Benefits of Narrative, Journal of Clinical Psychology, 55(10), 1243-1254.

http://doi.org/10.1002/(SICI)1097-4679(199910)55:10<1243::AIDJCLP6>3.0.CO;2-N

Redvisible (2014). La escritura y las emociones.

http://redvisible.com/la-escritura-y-las-emociones/ 
Reyes-Iraola, A. (2014). El uso de la escritura terapéutica en un contexto institucional. Revista Médica del Instituto Mexicano del Seguro Social, 52(5), 505-509. https://www.redalyc.org/articulo.oa?id=457745484010

Robin, C. (2009). El miedo. Historia de una idea política. FCE.

Rodríguez, M. (2011). Manual de escritura curativa. Almuzara.

Rogers, C. (1993). Psicoterapia centrada en el cliente. Paidós.

Rogers, C. (2007). El proceso de convertirse en persona. Paidós.

Selye, H. (1956). The Stress of Life. Mc Graw-Hill.

Smorti, A. (2001). El pensamiento narrativo. Construcción de historias y desarrollo del conocimiento social. Mergablum.

Stevens, J. (2006). El darse cuenta. Cuatro vientos.

Verd, J.M. \& Lozares, C. (2016). Introducción a la investigación cualitativa. Fases, métodos y técnicas. Síntesis.

White, M. \& Epston, D. (1993). Medios narrativos para fines terapéuticos. Paidós. 